\title{
Preliminary results of $\mathrm{TiO}_{2}$ mapping using Imaging Interferometer data from Chang' $E-1$
}

\author{
LING ZongCheng $^{1,2^{*}}$, ZHANG Jiang ${ }^{1,2}$, LIU JianZhong ${ }^{1}$, ZHANG WenXi ${ }^{3}$, ZHANG GuangLiang ${ }^{1}$, \\ LIU Bin ${ }^{1}$, REN Xin ${ }^{1}$, MU LingLi ${ }^{1}$, LIU JianJun ${ }^{1} \&$ LI ChunLai ${ }^{1}$ \\ ${ }^{1}$ National Astronomical Observatories, Chinese Academy of Sciences, Beijing 100012, China; \\ ${ }^{2}$ School of Space Science and Physics \& Shandong Provincial Key Laboratory of Optical Astronomy \& Solar-Terrestrial Environment, Shandong \\ University at Weihai, Weihai 264209, China; \\ ${ }^{3}$ Academy of Opto-Electronics, Chinese Academy of Sciences, Beijing 100080, China
}

Received March 3, 2011; accepted April 4, 2011

\begin{abstract}
The distribution of titanium abundance on the lunar surface is important knowledge for lunar geologic studies and future resource utilization. In this paper, we develop a preliminary model based on "ground truths" from Apollo and Luna sample-return sites to produce a titanium abundance map from Chang'E-1 Imaging Interferometer (IIM) images. The derived $\mathrm{TiO}_{2}$ abundances are validated with Clementine UVVIS results in several regions, including lunar highlands neighboring the Apollo 16 landing site, and high-Ti and low-Ti maria near the standard site of Mare Serenitatis (MS2). The validation results show that $\mathrm{TiO}_{2}$ abundances modeled with Chang'E-1 IIM data are overestimated for highlands $(\sim 0.7$ wt. $\%)$ and low-Ti maria $(\sim 1.5$ wt. $\%)$ and underestimated for high-Ti maria $(\sim 0.8 \mathrm{wt} . \%)$.
\end{abstract}

Chang'E-1, Imaging Interferometer (IIM), $\mathrm{TiO}_{2}$ mapping, Clementine UVVIS

Citation: $\quad$ Ling Z C, Zhang J, Liu J Z, et al. Preliminary results of $\mathrm{TiO}_{2}$ mapping using Imaging Interferometer data from Chang'E-1. Chinese Sci Bull, 2011, 56: 2082-2087, doi: 10.1007/s11434-011-4550-8

China's first lunar probe Chang'E-1 realized many achievements, including the recording of 4 terabytes of scientific data by eight payloads and various scientific returns [1]. Recently, several research groups have used Chang'E-1 data in their work [2]. For example, Li et al. produced the first imagery to fully cover the lunar surface using Chang'E-1 charge-coupled device (CCD) image data and constructed a global lunar digital elevation model with spatial resolution of $3 \mathrm{~km}$ based on laser altimeter data [3,4]. Ping et al. obtained a global topographic model based on laser altimeter data [5]. Fa et al. estimated the global inventory of helium-3 in lunar regolith using data from the multi-channel microwave radiometer [6]. Meng et al. attempted to calibrate data from the microwave radiometer and gained insights into mapping the water ice content in the Cabeus crater [7]. The

*Corresponding author (email: zcling@ @sdu.edu.cn) imaging interferometer (IIM), together with the gamma ray spectrometer, was used to detect the chemical and mineralogical compositions of the lunar surface [8-12]. Lunar UV/VIS (ultraviolet/visible)-NIR (near-infrared) spectroscopy has been widely used in lunar geologic studies since the 1970s, and was pioneered by telescopic observations [13]. Most lunar exploration missions have employed imaging spectrometers, such as the Clementine UVVIS/NIR [14], Kaguya Spectral Profile (SP) [15] and Changdrayaan-1 M3 [16] instruments. The main lunar minerals with typical absorption features in the $0.35-2.5 \mu \mathrm{m}$ spectral region contain $\mathrm{Fe}$ and $\mathrm{Ti}$ ions [17]. The visible-NIR reflectance characteristics of the Moon are sensitive to chemical, mineralogical, and physical properties of the lunar regolith, and have been widely used in lunar geological exploration [18]. The lunar Ti occurs mainly in opaque ilmenite $(\mathrm{FeTiO})$, and its distribution is important in understanding 
the petrogenesis of lunar rocks and thus the nature and origin of the Moon. Furthermore, ilmenite has been shown to be a promising resource for oxygen and metal production in future in-situ resource utilization [19].

The Chang'E-1 IIM data covers $78 \%$ of the global lunar surface and forms a valuable basis for future Chinese lunar missions [11]. Using data recorded by the IIM, Wu et al. produced a global absorption center map of mafic minerals on the Moon [20]. We have derived the FeO model and examined its potential for iron mapping using IIM data [12]. Liu et al. used two linear regression models to predict $\mathrm{Ti}$ content from absorption features extracted from IIM data for the region near the Apollo 17 landing site [21]. In this paper, we develop a new algorithm to map $\mathrm{TiO}_{2}$ abundance using Chang'E-1 IIM data, and then validate the results for several typical regions with Clementine UVVIS-derived $\mathrm{TiO}_{2}$ data.

\section{Algorithm for mapping $\mathrm{TiO}_{2}$ abundance}

\subsection{Clementine UVVIS method}

Before global lunar remote sensing missions were carried out, many researchers had studied the correlation between lunar color at UV/VIS wavelengths and the Ti content of the lunar surface [22,23], and found strong color differences between ultraviolet and visible-light regions on the lunar full disk, especially in maria. This color variation was suggested to be due to the principal compositional differences among mare basalts, namely the Ti content [23]. Charette et al. [24] showed that $\mathrm{TiO}_{2}$ abundance is correlated with telescopic measurements of the UV/VIS ratio $(0.402 \mu \mathrm{m} / 0.564$ $\mu \mathrm{m})$ in mature basaltic regolith. This relationship was used to predict $\mathrm{Ti}$ content for the unvisited mare regions. For emaxple, Charette suggested that the high- $\mathrm{TiO}_{2}$ mare basalts (e.g. in Mare Tranquillitatis) have flatter and "bluer" UV/VIS slopes than those with low- $\mathrm{TiO}_{2}$ mare basalts (e.g. at the standard site of Mare Serenitatis, MS2), which are spectrally "redder". The "Charette relation" provided the first quantitative comparisons of $\mathrm{TiO}_{2}$ for nearside mare regions, and was later refined by many researchers [25-28].

New $\mathrm{TiO}_{2}$ mapping methods were developed using Clementine and Galileo multispectral data. A series of empirical models have been developed to predict the $\mathrm{TiO}_{2}$ content from Clementine UVVIS images [29-32]. Among these models, Lucey's model has been one of the most popular and has undergone a series of refinements [33,34]. Lucey's method introduces a simple relation between the UV/VIS ratio $(415 \mathrm{~nm} / 750 \mathrm{~nm})$ and $\mathrm{TiO}_{2}$ content in soil of a mature mare to a titanium-sensitive parameter $\theta_{\mathrm{Ti}}$, an angular measure of the $\mathrm{TiO}_{2}$ content of soils taken from landing sites and sample stations in the plot of UV/VIS versus visible reflectance, to suppress the effect of maturity [29-32]. From analysis of Clementine UVVIS data, Lucey et al. [32] derived the following formula for $\theta_{\mathrm{Ti}}$ and thus wrote an algorithm to predict $\mathrm{TiO}_{2}$ content:

$$
\begin{aligned}
& \theta_{\mathrm{Ti}}=\arctan \left(\frac{R_{415} / R_{750}-0.42}{R_{750}}\right), \\
& \text { wt. } \% \mathrm{TiO}_{2}=3.708 \times\left(\theta_{\mathrm{Ti}}\right)^{5.979} .
\end{aligned}
$$

In this paper, we use Lucey's model to validate the $\mathrm{TiO}_{2}$ model for Chang'E-1 IIM data.

\subsection{Chang'E-1 IIM method}

The IIM aboard the Chang'E-1 lunar probe was a Fourier transform Sagnac imaging spectrometer. It had 32 spectral channels with spectral ranges from 480 to $960 \mathrm{~nm}$. The IIM was a pushbroom imaging spectrometer with a $512 \times 512$ pixel CCD detector to observe the Moon in polar circular orbit. When at an altitude of $200 \mathrm{~km}$ above the lunar surface, Chang'E-1 IIM yielded a ground resolution of 200 $\mathrm{m} /$ pixel and $25.6 \mathrm{~km}$ swath width. Detailed parameters can be found in $[11,12]$. IIM data used in this paper are level 2C in terms of radiometric calibration, photometric normalization and reflectance conversion. For the IIM reflectance conversion, a homogenous area (orbit 2225 line from 11117 to 11132 , sample from 124 to 128) on the Cayley Plains near the Apollo 16 landing site was selected as the calibration standard, and the spectra of Apollo 16 sample 62231 was used to calibrate the radiance to reflectance.

From the spectral pattern of ilmenite provided by Brown University RELAB (Figure 1), we find the absorption feature centered around $500 \mathrm{~nm}$, which is assigned to the electron transition of $\mathrm{Ti}^{3+}$ [35]. Thus, it is reasonable to use the nearby spectral channel of the IIM to predict the Ti content of the lunar surface. However, the spectral absorption feature of lunar soil is greatly reduced by "space weathering", i.e. the bombarding of lunar soil by micrometeorites, solar wind, and galactic cosmic rays, which act to produce agglutinates and nanophase iron $[18,36]$. Therefore, unlike Liu et al., who used the absorption feature of ilmenite in their $\mathrm{Ti}$ calculations [21], we used a Ti-sensitive parameter to suppress the space weathering effect in our calculations. Owing to the limited response of the CCD detector, the first five spectral channels of the IIM are of poor quality (i.e. a signal-to-noise ratio less than 10); thus, we choose B6 (522 $\mathrm{nm})$ and B24 $(757 \mathrm{~nm})$ instead of the Clementine UVVIS 415 and $750 \mathrm{~nm}$ bands to calculate the Ti content. As seen in Figure 1, B6 seems to be very near the absorption center of ilmenite; thus, it would be reasonable to use this spectral channel to calculate the Ti content.

The chemical contents of the lunar soil samples returned by Apollo and Luna missions are ground truths for lunar studies. We attempt to correlate the laboratory $\mathrm{TiO}_{2}$ contents of typical lunar soils with the remotely sensed multispectral images for individual sample stations. The method 


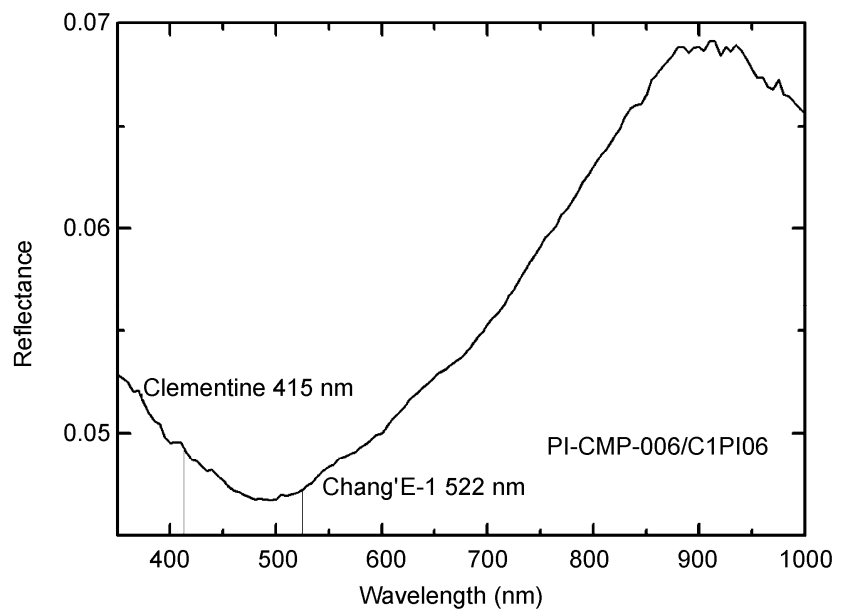

Figure 1 UVVIS/NIR spectrum of ilmenite from Brown University RELAB (sample number: PI-CMP-006/C1PI06).

for calculating the $\mathrm{TiO}_{2}$ abundance is similar to that employed by Lucey et al. [32]. The first step is to acquire spectra for the 38 Apollo and Luna sample stations (except Apollo 15 sites) covered by Chang'E-1 IIM data (the exact location can be found in a table of Lucey et al. [32]). In addition, the experience of Lucey et al. [32] showed that there are $\mathrm{TiO}_{2}$ content anomalies for Luna 16 and 24; thus, we discarded the data for these two sites and used data for the other 36 sample sites in regression. The spectral data for the 38 sample stations extracted from Chang'E-1 images are plotted in a diagram of ratio reflectance in Figure 2.

The key to the calculations is to suppress the maturity effect with an angle referred to as the Ti-sensitive parameter $\theta_{\mathrm{Ti}}$, which has a power-law relationship with $\mathrm{TiO}_{2}$ abundance. $\theta_{\mathrm{Ti}}$ is the angle between a line parallel to the $x$ axis and a line between the origin and data point, as indicated in Figure 2. Ilmenite is dark and spectrally neutral and would roughly plot near $(0.05,1.0)$ in Figure 2 (not shown) [32].

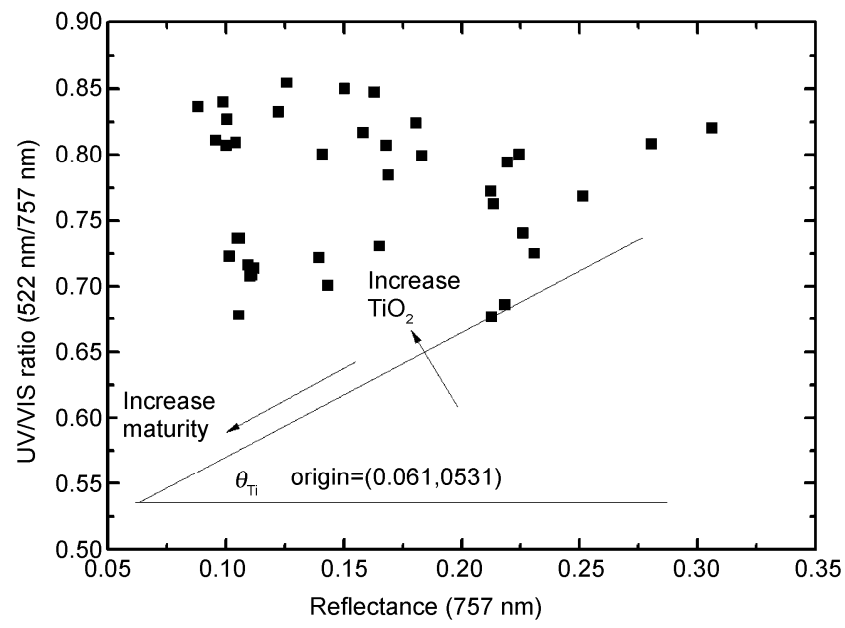

Figure 2 Spectral ratio $(522 \mathrm{~nm} / 757 \mathrm{~nm})$ versus reflectance $(757 \mathrm{~nm})$ plot for the sample stations observed by Chang'E-1 IIM.
Thus, a larger $\theta_{\mathrm{Ti}}$ refers to a point closer to the ilmenite end-member and thus increasing $\mathrm{TiO}_{2}$ as indicated in Figure 2. By maximizing the correlation between remotely measured $\theta_{\mathrm{Ti}}$ and $\mathrm{TiO}_{2}$ content, we obtain the origin at $(0.061$, 0.531 ), which yields a correlation coefficient of 0.86 .

We obtain an expression for $\theta_{\mathrm{Fe}}$ as follows:

$$
\theta_{\mathrm{Ti}}=\arctan \left(\frac{R_{522} / R_{757}-0.531}{R_{757}-0.061}\right) .
$$

Figure 3 is a plot of the $\mathrm{TiO}_{2}$ content and the spectral iron parameter. Eq. (4) is the best fit for these data points.

$$
\text { wt. } \% \mathrm{TiO}_{2}=1.158 \times\left(\theta_{\mathrm{Ti}}\right)^{5.364} \text {. }
$$

The standard deviation for the power-law fit is $1.56 \mathrm{wt} . \%$ $\mathrm{TiO}_{2}$, which is estimated as

$$
\sqrt{\frac{\sum\left(\mathrm{TiO}_{2, \text { predicted }}-\mathrm{TiO}_{2, \text { real }}\right)^{2}}{N-1}} .
$$

Note that the data points (see Figure 3) for Luna 16 and Luna 24 are well off the trend of other data; thus, they are removed in the regression. Additionally, the equation obtained is based on all available data for Apollo and Luna sites from the IIM, and it is thus suitable for global lunar $\mathrm{TiO}_{2}$ mapping. In this study, however, we concentrate on regional case studies to compare our model with Lucey's $\mathrm{TiO}_{2}$ model in detail with the intent to refine our model.

\section{Regional case studies}

Using our model (eqs. (3) and (4)) and the algorithm of Lucey [32], we can carry out regional case studies of the lunar surface. A Clementine UVVIS-derived $\mathrm{TiO}_{2}$ map based on Lucey's model [32] is also taken for comparison. We

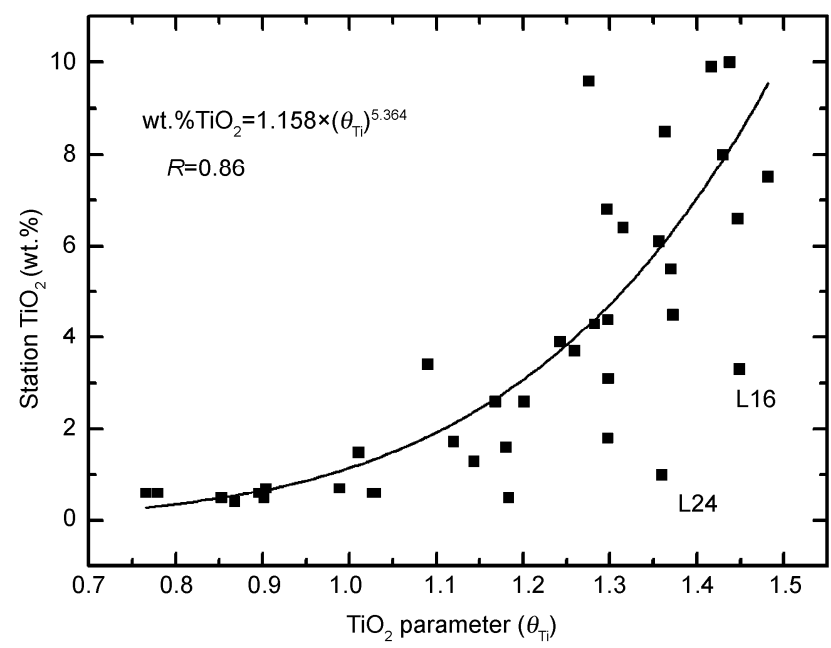

Figure $3 \mathrm{TiO}_{2}$ contents of the Apollo and Luna samples versus the spectral Ti-sensitive parameter $\theta_{\mathrm{Ti}}$. 
choose typical lunar highland and mare regions for case studies. In the case of highlands, a strip of the titanium map near the Apollo 16 landing site (as shown in Figure 4) was produced using IIM orbit 2225 data. The Apollo 16 landing site is important to spectral calibration [37]. It has also been used in the reflectance conversion of IIM data $[11,12]$. In the case of lunar maria, we chose a region near MS2, which has been used as an optical standard for telescopic studies [37]. We choose this region mainly because it is on the boundary of high and low titanium basalts; i.e. to the north is relatively uniform low-titanium mare basalt of Mare Serenitatis and to the south is a sharp boundary with older high-titanium mare basalt of Mare Tranquillitatis. Note that all IIM data have been resampled to $100 \mathrm{~m} /$ pixel for ease of comparison with Clementine UVVIS data.

Figure 4 shows the $\mathrm{TiO}_{2}$ distribution for highlands near the Apollo 16 landing site. We see that for relatively uniform lunar highland materials (highland plagioclase), the $\mathrm{TiO}_{2}$ content is very low; i.e. Clementine and Chang'E-1 images both show that the content is less than $4 \mathrm{wt} \%$. In the distribution histogram of $\mathrm{TiO}_{2}$ content (Figure 5), the $\mathrm{TiO}_{2}$ content predicted with Chang'E-1 IIM data is higher than that predicted with Clementine UVVIS data. The peak position for the Chang'E-1 IIM data is near 1.57 wt.\%, while the peak for Clementine data is near 0.9 wt.\%. The Chang'E-1 IIM data seem to distribute more widely than Clementine data (FWHM is $1.48 \mathrm{wt} . \%$ for IIM data and $0.31 \mathrm{wt} \%$ for Clementine UVVIS data). In general, the preliminary analysis of $\mathrm{TiO}_{2}$ in lunar highlands suggests that the IIM model overestimates by about $0.7 \mathrm{wt}$ \% relative to the Clementine model.

Lunar maria are well known for their enrichment in $\mathrm{Ti}$ due to ilmenite, which is the most abundant oxide mineral
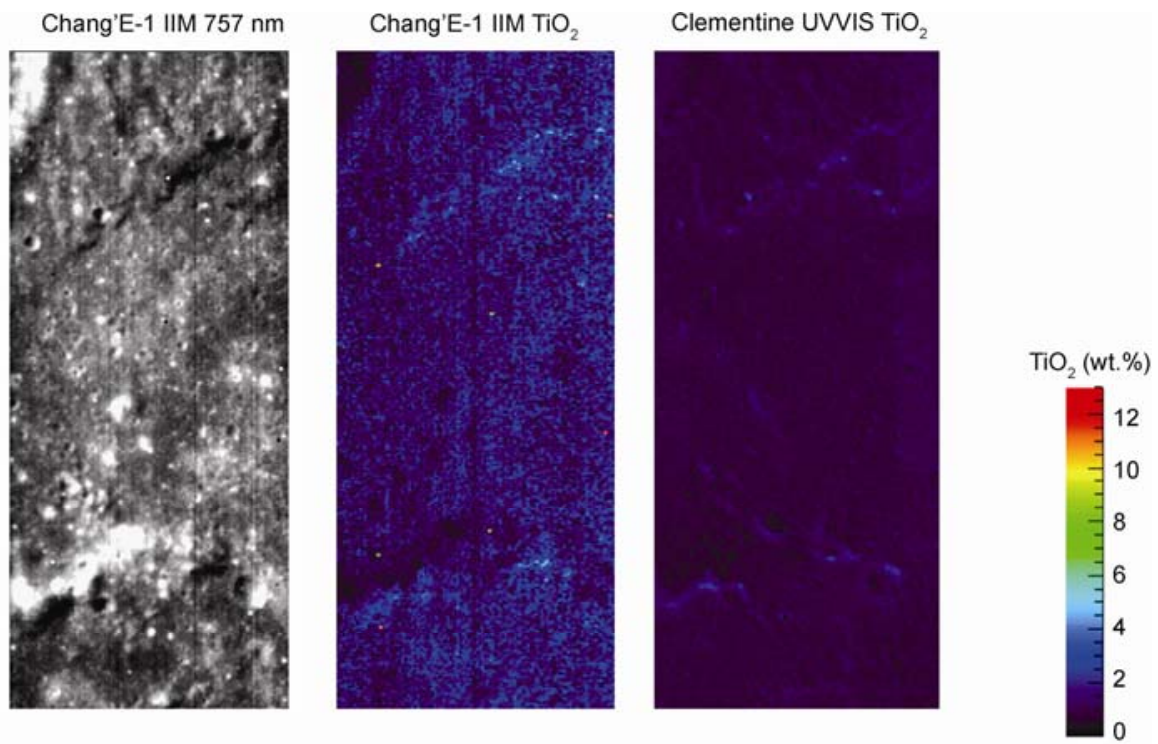

Figure 4 Comparisons of the titanium abundance maps of the Apollo 16 highland region derived with Chang'E-1 IIM and Clementine UVVIS images.

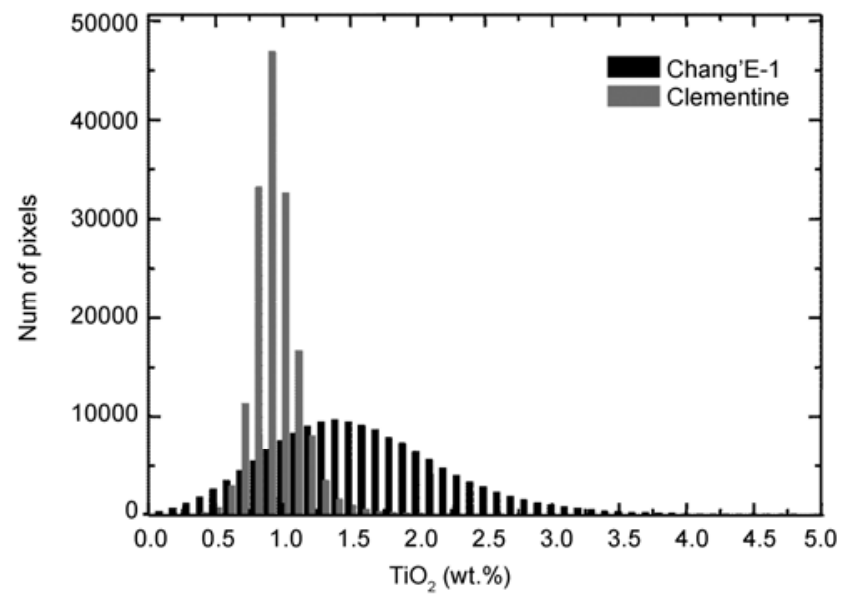

Figure 5 Data distribution in Chang'E-1 IIM and Clementine UVVIS images of the region near the Apollo 16 landing site. in lunar rocks. Mare Serenitatis in the southern part is on a boundary between low-Ti and high-Ti regions, which are referred to as lunar "red" and "blue" maria, respectively. In the IIM $757 \mathrm{~nm}$ mosaic, there is a distinct albedo difference between the two kinds of mare basalts. From the $\mathrm{TiO}_{2}$ map (Figure 6), it is easy to find the color difference boundary between "red" and "blue" maria, although not so clear as from Clementine data. As the data distribution histogram in Figure 7 indicates, the average values for Chang'E-1 IIM and Clementine UVVIS images are similar (about 7.39 wt.\% for IIM data and 7.25 wt.\% for Clementine data). However, Clementine data have an obvious bimodal distribution, with peaks at 5.94 wt.\% and 10.34 wt.\% associated with low-Ti and high-Ti regions in the images. The two peaks for IIM data are very close and not so distinguishable. By peak fitting of the histogram, we found the two peaks 

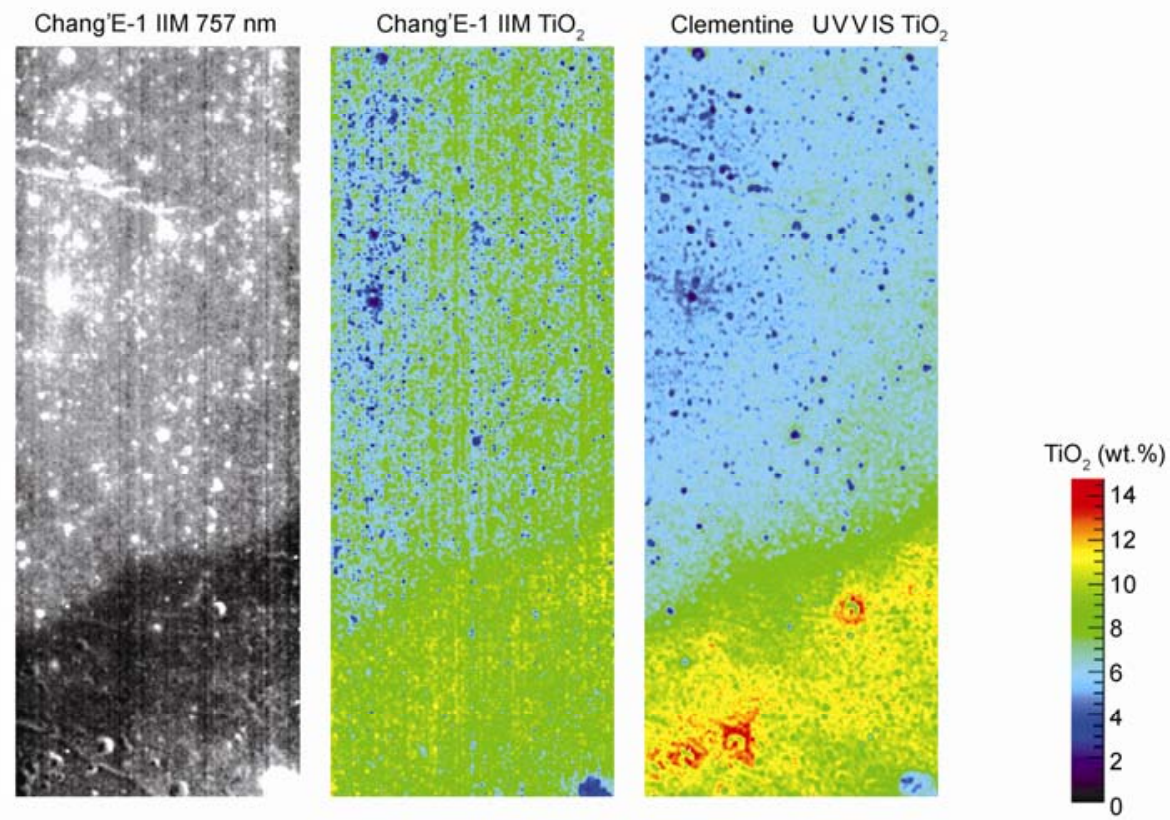

Figure 6 Comparisons of titanium abundance near the MS2 mare region derived from Chang'E-1 IIM and Clementine UVVIS images.

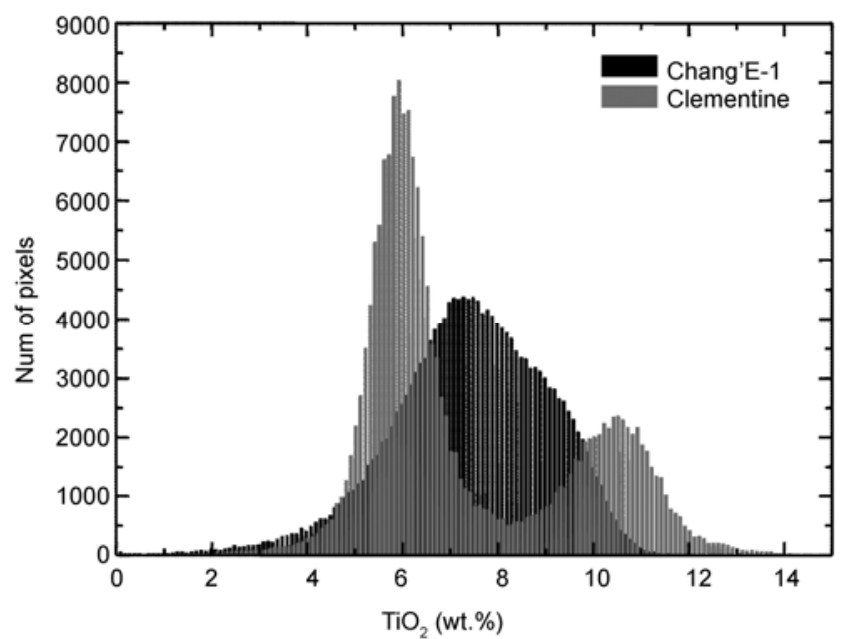

Figure 7 Data distribution of Chang'E-1 IIM and Clementine UVVIS images of the MS2 mare region.

are located at 7.42 wt. $\%$ and 9.5 wt.\%. In general, our model overestimates the low-Ti region by $\sim 1.5 \mathrm{wt} . \%$ while it underestimates the high-Ti regions by $\sim 0.8 \mathrm{wt} . \%$. There may be various reasons for the discrepancies. First, IIM data did not cover the Apollo 15 landing site and our model thus lacks input parameters for regions with relatively low-Ti basalt. Relatively poor estimation of a low-Ti mare region would be expected using Chang'E-1 IIM data. Second, we chose the band at $522 \mathrm{~nm}$ for the regression calculations (not the $415 \mathrm{~nm}$ band as Lucey did [32]). This may decrease the sensitivity of our model considering the space weathering effects of lunar soil. In addition, the relatively poor quality of IIM data (lower signal-to-noise ratio) and topographic shading effects are potential reasons for the discrep- ancies between Chang'E-1 and Clementine data.

\section{Conclusions}

The derivation and applications of a preliminary algorithm for $\mathrm{TiO}_{2}$ mapping using Chang'E-1 IIM data were presented in this paper. Using data for 36 sample stations obtained by Chang'E-1 IIM, we derived a power-law formula to extract the lunar surface $\mathrm{TiO}_{2}$ content. By comparing with Clementine UVVIS results, Chang'E-1 IIM data can be used to extract the distribution of the $\mathrm{TiO}_{2}$ abundance on the Moon. Highland and mare regional studies suggested that the $\mathrm{TiO}_{2}$ map derived using our model has good correlation with Clementine UVVIS results in corresponding areas. However, detailed studies suggest an overestimate $(\sim 0.7$ wt. $\%)$ of $\mathrm{TiO}_{2}$ content in the studied highland area, an overestimate $(\sim 1.5 \mathrm{wt} . \%)$ in the lunar low-Ti mare region, and an underestimate $(\sim 0.8 \mathrm{wt} . \%)$ in the lunar high-Ti mare region. We will continue to refine our $\mathrm{TiO}_{2}$ model to improve its prediction ability.

This work was supported by the National High-Tech Research and Development Program of China (2008AA12A212/211/213, 2009AA122201, 2010AA122203), China Postdoctoral Science Foundation (20090450580) and National Natural Science Foundation of China (11003012).

1 Ouyang Z Y, Li C L, Zou Y L, et al. Chang'E-1 lunar mission: An overview and primary science results. Chin J Space Sci, 2010, 30: 392-403

2 Ping J S. Preface: Joint researches are benefiting the Chang'E-1 comprehensive lunar scientific studies which probe ever deeper. Sci 
China Phys Mech Astron, 2010, 53: 2135-2135

3 Li C L, Liu J J, Ren X, et al. The global image of the Moon obtained by the Chang'E-1: Data processing and lunar cartography. Sci China Earth Sci, 2010, 53: 1091-1102

4 Li C L, Ren X, Liu J J, et al. Laser altimetry data of Chang'E-1 and the global lunar DEM model. Sci China Earth Sci, 2010, 53: 15821593

5 Ping J S, Huang Q, Yan J G, et al. Topographic model CLTM-s01 of the Moon based on laser altimetry of CE-1 probe. Sci Chin Ser G-Phys Mech Astron, 2008, 38: 1601-1612

6 Fa W Z, Jin Y Q. Global inventory of Helium-3 in lunar regoliths estimated by a multi-channel microwave radiometer on the Chang-E 1 lunar satellite. Chinese Sci Bull, 2010, 55: 4005-4009

7 Meng Z G, Chen S B, Edward M O, et al. Research on water ice content in Cabeus crater using the data from the microwave radiometer onboard Chang'E-1 satellite. Sci China Phys Mech Astron, 2010, 53: 2172-2178

8 Zheng Y C, Ouyang Z Y, Li C L, et al. China's lunar exploration program: Present and future. Planet Space Sci, 2008, 56: 881-886

9 Ouyang Z Y, Jiang J S, Li C L, et al. Preliminary scientific results of Chang'E-1 lunar orbiter: based on payloads detection data in the first phase. Chin J Space Sci, 2008, 28: 361-369

10 Sun $\mathrm{H} \mathrm{X}, \mathrm{Wu}$ J, Dai S W, et al. Introduction to the payloads and the initial observation results of Chang'E-1. Chin J Space Sci, 2008, 28: 374-384

11 Ling Z C, Zhang J, Zhang W, et al. Chang'E-1 IIM reflectance conversion. In: Global Lunar Conference, 2010, 5819

12 Ling Z C, Zhang J, Liu J Z, et al. Preliminary results of FeO mapping using imaging interferometer data from Chang'E-1. Chinese Sci Bull, 2011, 56: 376-379

13 McCord T B, Adams J B. Progress in optical analysis of lunar surface composition. Moon, 1973, 7: 453-474

14 Nozette S, Rustan P, Pleasance L P, et al. The Clementine mission to the Moon-Scientific overview. Science, 1994, 266: 1835-1839

15 Matsunaga $\mathrm{T}$, Ohtake M, Haruyama J, et al. Discoveries on the lithology of lunar crater central peaks by SELENE spectral profiler. Geophys Res Lett, 2008, 35: L23201

16 Pieters C M, Boardman J, Buratti B, et al. The Moon mineralogy mapper (M-3) on Chandrayaan-1. Curr Sci, 2009, 96: 500-505

17 Burns R. Mineralogical Applications of Crystal Field Theory. Cambridge, UK: Cambridge University Press, 1993

18 Lucey P, Korotev R L, Gillis J J, et al. Understanding the lunar surface and space-Moon interactions. Rev Miner Geochem, 2006, 60: 83-219

19 Heiken G, Vaniman D T, French B M. Lunar Sourcebook: A User's Guide to the Moon. Cambridge, UK: Lunar and Planetary Institute and Cambridge University Press, 1991

20 Wu Y Z, Zhang X, Yan B K, et al. Global absorption center map of the mafic minerals on the Moon as viewed by CE-1 IIM data. Sci China Phys Mech Astron, 2010, 53: 2160-2171

21 Liu F J, Qiao L, Liu Z, et al. Estimation of lunar titanium content:
Based on absorption features of Chang'E-1 interference imaging spectrometer (IIM). Sci China Phys Mech Astron, 2010, 53: 2136-2144

22 McCord T B. Color differences on lunar surface. J Geophys Res, 1969, 74: 3131-3142

23 Whitaker E. Lunar color boundaries and their relationship to topographic features: A preliminary survey. Earth Moon Planets, 1972, 4: 348-355

24 Charette M P, Mccord T B, Pieters C M, et al. Application of remote spectral reflectance measurements to lunar geology classification and determination of titanium content of lunar soils. J Geophys Res, 1974, 79: 1605-1613

25 Johnson J R, Larson S M, Mosher J A. A $\mathrm{TiO}_{2}$ abundance map for the northern maria. In: Proceedings of 8th Lunar Science Conference, 1977, 1029-1036

26 Johnson J R, Larson S M, Singer R B. Remote sensing of potential lunar resources. 1 Near side compositional properties. J Geophys Res, 1991, 96: 18861-18882

27 Pieters C M. Mare basalt types on the front side of the Moon: A summary of spectral reflectance data. In: Proceedings of 9th Lunar Planet Science Conference, 1978, 2825-2849

28 Melendrez D E, Johnson J R, Larson S M, et al. Remote sensing of potential lunar resources. 2 High spatial resolution mapping of spectral reflectance ratios and implications for near side mare $\mathrm{TiO}_{2}$ content. J Geophys Res, 1994, 99: 5601-5619

29 Blewett D T, Lucey P G, Hawke B R, et al. Clementine images of the lunar sample-return stations: Refinement of $\mathrm{FeO}$ and $\mathrm{TiO}_{2}$ mapping techniques. J Geophys Res, 1997, 102: 16319-16325

30 Lucey P G, Blewett D T, Hawke B R. Mapping the $\mathrm{FeO}$ and $\mathrm{TiO}_{2}$ content of the lunar surface multispectral imagery. J Geophys Res, 1998, 103: 3679-3699

31 Jolliff B L. Clementine UVVIS multispectral data and the Apollo 17 landing site: What can we tell and how well? J Geophys Res, 1999, 104: 14123-14148

32 Lucey P G, Blewett D T, Jolliff B L. Lunar iron and titanium abundance algorithms based on final processing of Clementine ultraviolet-visible images. J Geophys Res, 2000, 105: 20297-20305

33 Gillis J J, Jolliff B L. A revised algorithm for calculating $\mathrm{TiO}_{2}$ from Clementine UVVIS data: A synthesis of rock, soil, and remotely sensed $\mathrm{TiO}_{2}$ concentrations. J Geophys Res, 2003, 108: 5009

34 Gillis J J, Lucey P G, Hawke B R. Testing the relation between UV-vis color and $\mathrm{TiO}_{2}$ content of the lunar maria. Geochim Cosmochim Acta, 2006, 70: 6079-6102

35 Adams J B, McCord T B. Optical properties of mineral separates, glass, and anorthositic fragments from Apollo mare samples. In: Proceedings of 2nd Lunar Planet Science Conference, 1971, 21832195

36 Ling Z C, Wang A, Jolliff B L. Mineralogy and geochemistry of four lunar soils by laser-Raman study. Icarus, 2011, 211: 101-113

37 Pieters C M, Head J W, Isaacson P, et al. Lunar international science coordination/calibration targets (L-ISCT). Adv Space Res, 2008, 42: $248-258$

Open Access This article is distributed under the terms of the Creative Commons Attribution License which permits any use, distribution, and reproduction in any medium, provided the original author(s) and source are credited. 